\title{
UTP-Hexose-1-Phosphate Uridylyltransferase Deficiency
}

National Cancer Institute

\section{Source}

National Cancer Institute. UTP-Hexose-1-Phosphate Uridylyltransferase Deficiency. NCI

Thesaurus. Code C99104.

An inherited metabolic disorder characterized by increased levels of galactose in the blood. Clinical signs include failure to thrive, developmental delays, liver damage and jaundice, cataract, and ovarian failure. 